\title{
Specificities, Obstacles and Limits to Building Customer Loyalty in Mountain Resort Luxury Hotels
}

\author{
Maud Tixier \\ ESSEC Business School Paris-Singapore, Cergy-Pontoise, France \\ E-mail: tixierm@essec.fr \\ Received March 30, 2011; revised May 6, 2011; accepted June 21, 2011
}

\begin{abstract}
Customer loyalty in mountain resort luxury hotels is truly challenging; it presents specificities, obstacles and limits. We shall base our findings on the example of Courchevel, located in the Savoie region, in France, a resort renowned worldwide for its concentration of luxury and 5-star hotels with their star-winning chefs that testify to this. One rarely mentions customer loyalty there and the concept remains intuitive and empirical; it would require finer analyses, genuine competences and a better adapted communication. We shall in turn study the limits brought to the following aspects: profitability, staff loyalty, new technologies, promotion and communication, the evolution of the expectations of rich customers, of the gilded youth, gastronomy, innovation in services, the successive waves of foreigners... in a post-recession context in which the codes of luxury have evolved. Fifty or so qualitative interviews on the topic of customer loyalty were carried out in twenty or so hotels for this study between 2008 and 2010.
\end{abstract}

Keywords: Luxury Mountain Resorts, Customer Loyalty

\section{Introduction}

No one today disputes the importance of building customer loyalty, whether in the hospitality business or otherwise; there are significant stakes at play since it is often understood and proven that it costs twice as little to keep the patronage of a customer rather than to win him or her over... (Reichheld-Sasser, 1990; Thomas, 2001) $[1,2]$

There are however very specific interesting situations worthy of study than can be very educational, as well as rarely mentioned cases in which customer loyalty can be questioned. We shall observe such cases in this article.

Let us first study the particular situation of luxury hotels in a world-renowned French ski resort located in the Alps, namely Courchevel; it sets high standards in terms of customer loyalty ( $50 \%$ on average) since up to four successive generations often patronize the same hotels; there are however many obstacles.

Among these obstacles, the recession rates high alongside the evolution of customer behaviour, the increased fast-changing consumer habits of younger generations, an independent seasonal and top-of-the-range hospitality sector which is harder-hit than other segments, a record of successive waves of rich foreigners also affected by their own history, a near absence of classical methods of customer loyalty developed in chain hotels yet these hotels experience nonetheless the same limits.

This is what we propose to broach here, both from the customer and hotel manager perspective or from the customer and staff perspective.

\section{Methodology}

In order to do this, we have carried out fifty or so qualitative interviews in twenty 4-star and luxury 4-star hotels (that landed a 5th star in 2010) as well as a single 3-star hotel belonging to the Accor chain for the sake of comparison (21 therefore in total). These were completed by the interviews of further players and decision makers such as the successive mayors, the managers of ski lifts $(\mathrm{S} 3 \mathrm{~V})$, the ski instructors to wealthy regulars and both foreign and French customers.

It turns out many hindrances paved the way to the success of this venture: reluctance on the part of hotel managers to broadcast their communication and customerloyalty strategies because of the competition, lack of time linked to the seasonality, near impossibility to access the highly protected customers of luxury hotels, cant regarding the occupancy rate $(85 \%$ on average) but 
which is not supplied for each hotel, absence of reliable statistical data on the scale of a given hotel etc...

Moreover certain hotels are too recent in terms of their management to be interviewed on their customer-loyalty programmes. Besides, even when isolating the sole chain hotel of the resort (Le Mercure, Accor Group), one must also distinguish among the independent hotels those managed by the original families from those belonging to financial holdings or to wealthy foreigners; the latter run by managers rather than by owner families but these can nonetheless remain very much part of the picture.

Abundant reading material is available on the subject of customer loyalty. That concerning Courchevel is mainly focused on the existing links between homogeneous social groups who enjoy mingling (Mc Alexander; Schouten, \& Koenig 2002; Muniz \& O’Guinn 2001; Morais, Kerstetter \& Yarnal 2006) [3-5].

However, there is next to nothing regarding the drawbacks linked to die-hard customer loyalty strategies, indeed even its adverse effects although these clearly came to light in the course of the interviews. This is what we shall be recounting here.

\subsection{Pre- and Post-Recession}

Until the 2007-2008 season, for which bookings had been organised long ahead, the situation had been very stable: customers booked from one year to the next, by the week ${ }^{1}$, failing to question the period of their stay or the choice of their hotel, and paid a deposit for this privilege.

One knew they would simply turn up. The 2008 recession emphasized the trends that spread to the whole tourism sector: last minute bookings, shorter, less frequent and divided-up stays, haggling or price decreases, resulting in more random loyalty. Previously, hotel managers were even in a position to select their customers. Nowadays, they must renew them or develop customer loyalty by engaging more effort in a high-end sector which is struggling to take off again and an independent hospitality business which is suffering ${ }^{2}$. Those customers erstwhile won over are today more flighty.

\subsection{The Disaffection and the Successive Waves of Foreigners}

The major mountain resorts were more affected by the recession when they were international because of the defection of foreign markets, notably British, Belgian

\footnotetext{
${ }^{1}$ At the Airelles, one could wait up to 8 years for a suite booked for two weeks during the Xmas holiday season!

${ }^{2}$ The ProfPAR (Profit per available room) of 4-star hotels has declined from $15 \%$ to $18 \%$ in 2009 according to the Protourisme Studies, Deloitte and KPMG, 2009.
}

and Dutch. The high-end hotel business was therefore seriously harmed since it is highly sensitive to the flows of foreign customers renowned for their high volatility.

Following the commercial canvassing, the wars ${ }^{3}$, the scandals ${ }^{4}$ and the economic recessions, the waves of wealthy foreigners have always succeeded one another in a resort such as Courchevel.

Hence the Americans, followed by the Lebanese, the Russians and the inhabitants of the Middle-East patronized the resort, left, returned in some cases, which constituted both a blessing and a risk for the resort. The Anglo-Saxons seemingly belong to the most versatile segment; there are Turkish, Brazilian, Venezuelan, English, Russian, Spanish... weeks. Those who set foot in the resort for the first time may want to change hotels out of curiosity before settling down, notably with the increase in the luxury hotel offer (it has doubled over the last 10 years). Those successive waves of international customers compel hotel managers not to build customer loyalty but rather to travel the world to lure new customers. They canvas by going on promotional tours from July to November, at a very high cost, to South America, Turkey, Brazil, Israel, Mexico, Great Britain, Lebanon, Central Europe...

Women, who, according to studies (Backmann, 1988; Petrick and Backman, 2001; Kerstetter, Bricker and Gitelson, 2000) [6-8] are both more loyal on an emotional level and often make leisure-oriented decisions, constitute a substantial population in terms of the development of customer loyalty. All these cultures have besides very different notions of luxury which are hard to combine in a single setting.

\subsection{Customers Have Changed}

- Tradition and Modernity: the subtle balance between tradition and modernity may no longer suit the regular loyal customers; this may be noticeable in catering, room refurbishment and all the services on offer. Being constantly attentive is a true school of life...

- $\quad$ Satisfied fickle customer: one is too familiar with his or her habits and tastes; he or she has explored everything the hotel has to offer; he or she is keen on novelty; one must reckon with his or her weariness, forgive him or her for changing hotels since he or she may be back and spread the word, therefore he or she must be turned into a loyal customer!

- The zeitgeist: customers are today more openly

\footnotetext{
${ }^{3}$ For instance in Kuwait in 1992.

${ }^{4}$ For instance, Samsung, Prokhorov who later spurned the resort as did those foreigners who were tired of being ripped off by certain shopkeepers or restaurants.
} 
critical; they are no longer reluctant to give their opinion on the quality of the service, on the cost of a service and have become far fussier about the quality-price ratio. They need to become involved and vent their feelings

- Intimacy and exclusivity: those are the new needs of customers seeking a hotel offer that is both complementary and different: privatized chalets, a home away from home, luxurious serviced apartments... the new competition offering more exclusive, intimate, sophisticated packages has compelled traditional hotels to question their strategies in order to confront the competition.

- New luxury codes: the financial recession has triggered a sustainable change in the consumer habits of luxury hotel customers. The latter seek more authenticity, less "blingbling". Flaunting one's wealth and spending freely are deemed indecent; the page of excess has been turned; elegant restraint is appropriate; hotel managers are therefore striving for the fine line between exclusivity and an overly ostentatious luxury, which is hard to pin down.

Hotel managers will be compelled to adapt their offer to all those new behaviours in order to develop customer loyalty among rich international would-be patrons.

\subsection{The Evolution of Taste among the Gilded Youth}

This may constitute a setback to building customer loyalty which led four successive generations of a single family to patronize the same hotel from one year to the next, season after season. Not only are these disloyal, but their conception of luxury has changed tremendously. Luxury has become more individual than social and the symbolic dimension remains the unifying element. It is a question of personal indulgence for the "sneaker-wearing affluent" as they are known.

This new generation of 30 -something enterprising people contributes to breaking the traditional codes; they disturb by their seemingly contradictory requirements striving after a different kind of well-being. In their mind, hotel managers will need to outshine each other in terms of ingenuity, to propose increasingly luxurious, trendy and intimist products. Those hotels in a position to offer all of this are few and far between and new rival luxury hotels are emerging on the market; historical luxury hotels will therefore need to react, just like the Royal Monceau in 4 Paris $^{5}$, which elected to rethink its structure and

\footnotetext{
${ }^{5}$ In Paris, one can also list the future Mandarin Oriental, the Shangri-la and the Peninsula. Study by the Jones Lang Lasalles Hôtels firm on "The Parisian Luxury Hotels by 2015 " by L. Barneville, Quotidien du Tourisme, August 282008.
}

its codes in order to carry on attracting customers and building loyalty.

Hence the image of luxury hotels will need an injection of new blood: renovation of the buildings, contemporary art, trendy bars intermingling customers, appealing to individuals from business, literary, political and artistic circles ${ }^{6}$, wild and artistic parties upsetting the hushed tradition of the legendary bars of luxurious hotels, in a nutshell new-age revamped luxury embodying the zeitgeist and the spirit of a place in a relaxed atmosphere $^{7}$.

\subsection{Staff Loyalty}

Although staff loyalty often goes hand in hand with customer loyalty, one can note that in high-end hotels, staff loyalty even prevails over customer loyalty. It reassures customers from one stay to the next. The management of seasonal employees raises nonetheless many issues in resorts.

It is indeed difficult to hire seasonal employees for the duration of the four winter months.

Recruitment begins as early as July and the locals are few and far between. Many stem from Brittany, Corsica, the South-East of France or Paris. All must be fluent in English. When they resign during the season, they cannot be replaced. Hotel managers therefore make sure to hire approximately $25 \%$ additional staff compared to their needs at the start of the season.

Training, behaviour, accommodation issues often crop up. Among them: learning to greet guests constitutes a basic rule, de-escalating upsets likely to weaken the waiting staff, and this unbeknownst to the customers.

Among frequent issues, one can list waiting staff imitation: they adopt the behaviour of rich customers and squander their monthly pay in a single evening. The sole issue of waiters or waitresses living in substandard accommodation may disrupt the whole team and up to the customers. The loyalty rate varies between $50 \%$ and $60 \%$ in the most renowned hotels ${ }^{8}$.

Besides, the outrageous tips left by very wealthy foreign customers may raise issues; these are disproportionate to the wages and unbalance the relations with the other local populations or holiday-goers.

The perception wealthy customers have of the service has evolved with the new work legislation which has modified the behaviour of seasonal staff, who are no

\footnotetext{
${ }^{6}$ In Courchevel, in the Strato, the Cheval Blanc, the Sivolière - In Paris at the Ritz, at the Plaza Athénée.

${ }^{7}$ Like for instance in Courchevel at the Airelles and the Melezin where notably the Russians have changed the atmosphere into something more relaxed.

${ }^{8} 50 \%$ corresponds to the average in the sector yet is exceptional in a four-month only seasonal framework.
} 
longer close to the customers. All the small details revolving around the tastes of regular customers which made all the difference are no longer taken into account, which pushes customers to declare they no longer enjoy the service they were accustomed to. Yet the quality of the service is more natural in rival resorts whether in Switzerland or Austria, which impacts not only hotel managers, but also the ski lift staff and the shopkeepers.

The ability for any staff member to provide high quality service implies appropriate training and the acceptance of his or her status as an "underling" i.e. someone totally devoted to waiting on posh customers. This in France does not go without saying. It raises the issue of staff loyalty, which is far less risk-inducing for management if the latter is aware how he or she will behave towards customers. As a result management is compelled to hire more members of staff than it actually requires in order not to lose customers.

\subsection{An Escalation through Innovation and Services}

The permanent improvement process is nearly compulsory. Each wave of refurbishment sets new higher standards of service as famed interior decorators, designers and star-winning chefs are enrolled, luxurious spas created... To build customer loyalty, luxury hotels cannot bypass a wellness centre and a cuisine on par with the expectations of those customers and of the cutthroat competition which is customary on this niche. A luxury hotel must provide its guests with relaxation and leisure opportunities, tools of seduction-a spa, a gourmet restaurant - to develop customer loyalty and increase the duration of stays, win points in terms of occupancy, renew its customers notably in mountain resorts when ageing customers do not always come to ski...

Each fall, hotels communicate to their customers by mail all the improvements and changes on offer for the following season: new chef, smoking room, pillow menu, beauty treatments, made-over decoration, revamped interior design, play area, projection room, zany bar, stars won for the hotel or the catering, improved connectivity, improved quality of sound, furniture mobility, extreme customization of services and better preserved intimacy...

The escalation may testify to a lot of innovation as it may also surprise, seduce all over again, spark off oneoff experiences and thus differentiate from the competition in order to stand out [9].

When innovative factors are placed in relation with contemporary academic literature (Flipo 2001, Jallat 1994, Martins and Terblanche 2003) [10-12] describing the models of the culture of innovation, hotel managers will need to contend with the fact that they will never succeed in building alone loyalty among high-end customers. Indeed, one does not develop customer loyalty via innovation since it is systematically copied and must hence be replaced by further innovation... quite a costly process!

Customer loyalty is entirely built on the ability to provide service. The possible service potential demanded and always available requires customer awareness, competence on the part of all the players of the system and customer respect. The level of service is based both on the availability of services on offer and on how competently they are provided. The constant exertion of pressure following all potential requests requires qualification and competence on the part of all employees, at all levels. Meeting these expectations is the priority for any luxury hotel and will have more or less impact according to their discriminatory and differentiating character compared to the competition.

\subsection{Gourmet Excesses?}

In the 2010 edition of the Michelin guide, four new restaurants were awarded stars in Courchevel. Boasting seven star-rated restaurants, the resort now is one of the spots in the world with the most star-awarded restaurants per $\mathrm{m}^{2}$. This brings about two drawbacks: firstly, strengthening communication stances around luxury, which tends to emphasize the sumptuous image of the resort, which lies opposite the actual diversity of the offer and repels ordinary customers; secondly, among rich customers themselves who tire of an exclusive gourmet offer in some hotels. Too much gastronomy might end in gastronomy overkill and keep less rich yet similarly sought-after customers at bay.

\subsection{The Relationship between Loyalty and Profit}

It is not always as strong as hoped for. Indeed, according to Werner Reinartz's computations [13], the correlation between the two averaged 0.20 to 0.45 on a scale of 1.00 , i.e. a low to moderate 6 level; loyal customers do not cost the hotel less and do not spend more than the others; they generate in fact little marginal income and are aware of the best deals... Some hotel managers find them more demanding and underline the necessity of connecting loyalty and profitability by no longer investing on certain customers who are no longer worthwhile [14]. This is quite easy for luxury and high-end hotels for which qualitative observations can easily be kept and exploited 
on a case by case basis (i.e. "one to one") ${ }^{9}$. This approach may help rethink the fixed cost structure in order to adapt it to the evolution of the turnover according to the season, lead to the reassessment of quality standards, which is not usually consistent with the culture of the high-end category.

\subsection{A Limited Use of Technologies}

Chain hotels invest in technology to increase customer loyalty. This is seldom the case among luxury hotels in Courchevel which are often independent and familyowned. They will not consider inundating their customers with emails or marketing offers whereas they are more attuned to protecting privacy and even less forcefully collecting information by interrogating their customers ${ }^{10}$. Internet-fuelled customer loyalty remains under-developed or at the least not very visible; few means are generally devoted to the web although new technologies contribute a new dimension and open numerous perspectives for an increasingly customized marketing.

Besides, the sector resorts to other networks such as Relais et Chateaux, Small Luxury Hotels

(SLH) or Leading Hotels of the World (LHW), worldwide renowned labels, to compensate for the absence of traditional customer loyalty schemes that are ill-suited as well as loyalty strategies with a strong less commonplace relational dimension.

\subsection{A Restrained Use of Communication}

Communication with customers generally bypasses, as we have pointed out, new technologies; these are also limited by the seasonality of trade (four months per year). As a result, customers remain for months on end with no news from the hotel that could be developing their loyalty.

Sometimes the hotel managers, in a joint effort with the Office du Tourisme, meet customers at home on the occasion of a meeting in the framework of promotional tours. These means to seduce and build customer loyalty are very expensive and come in addition to the gifts the customers receive upon departure to thank them for their patron that season.

They are contacted once more over the summer to be informed of the improvements to the services for the upcoming season: major works, new spa, child area, makeover etc... A new positive message to reassure and make them dream.

${ }^{9}$ For instance, the "Infiniment" programme by Lucien Barrière, designed to cater to the implemented relational marketing.

${ }^{10}$ The advantage is that the database does not run the risk of being illused.
But communication, even when it is more intensive, would fail to sustainably build loyalty among educated, demanding and world-wary customers... the requisite reflection prior to a strategic communication is all too often neglected, even ignored in luxury hotels.

\section{Conclusions}

Customer loyalty in luxury hotels in mountain resorts is a challenge; it has its specificities, its obstacles and also its limits. This study has enabled us to identify the shortcomings whose effects are even more acute in a postrecession era with tougher competition. According to many hotel managers, nowadays the luxury hotel offer is too important for a resort such as Courchevel.

Oddly enough, hotel managers seldom mention customer loyalty whose methods remain intuitive and empirical. Few studies are available on the subject and each hotel manager wants to jealously keep his or her customers without communicating figures... The cost of customer loyalty is very high, as is canvassing other rich customers. Genuine competences and finer-tuned analyses on their part would most probably not spare them from having to resort to the canvassing, yet further research might contribute to it. The role of a better adapted communication deserves to be looked into. It is likely that on the short run, hotel managers themselves, in order to build loyalty, will carry on making huge efforts by travelling the world and by investing in the impeccable quality of their welcome and of the services on offer.

\section{References}

[1] F. Reicheld and W. E. Sasser, "Zero Defections: Quality Comes to Services," Harvard Business Review, Vol. 68, No. 5, 1990, pp. 105-111.

[2] J. S. Thomas, "A Methodology for Linking Customer Acquisition to Customer Retention," Journal of Marketing Research, Vol. 38, No. 2, 2001, pp. 262-268. doi:10.1509/jmkr.38.2.262.18848

[3] J. H. Mc Alexander, J. W. Schouten and H. F. Koenig, "Building Brand Community," Journal of Marketing, Vol. 66, No. 1, 2002, pp. 38-54. doi:10.1509/jmkg.66.1.38.18451

[4] A. M. Muniz and T. C. O'Guinn, "Brand Community," Journal of Consumer Research, Vol. 27, No. 4, 2001, pp. 412-432. doi: $10.1086 / 319618$

[5] D. Kerstetter, D. B. Morais and C. M. Yarnal, "The Love Triangle: Loyal Relationships among Providers, Customers, and their Friends," Journal of travel Research, Vol. 44, No. 4, 2006, pp. 379-386. doi: $10.1177 / 0047287505282955$

[6] S. J. Backman, "The Utility of Selected Personal and Marketing Characteristics in Explaining Consumer Loy- 
alty to Selected Recreation Services," Ph.D. Dissertations, Texas A \& M University, College Station, 1988.

[7] J. F. Petrick and S. J. Backman, "An Examination of Golf Travelers' Satisfaction, Perceived Value, Loyalty and Intentions to Revisit," Tourism Analysis, Vol. 6, No. 3/4, 2001, pp. 223-237.

[8] D. Kerstetter, K. Bricker and R. Gitelson, "The Influence of a Spouse or Partner in Travel Decision-Making," Visions in Leisure and Business, Vol. 18, No. 3, 2000, pp. 51-55.

[9] M. Phan, "Innovation in Terms of Services," Decisions Marketing No. 48, October-December 2007.

[10] J. P. Flipo, "L'innovation dans les activités de service:

\section{Appendix}

\section{Professionals Interviewed (1 to 3 Times Each)}

Bertrand Jean Jack, Baiada Clotilde, Blanc-Tailleur Gilbert, Bottelin Dominique, Bricaud Christophe, Clareton Laurent, Debernard Henri, Dumont Nicolas, Durant Terrasson Roland Claude, Durandard André, Faure Claude, Gormier Christophe, Guimbaud Jerôme, Jacob JeanPierre, Laverge Elizabeth, Mugnier Fernand, Mugnier Philippe, Munier Thierry, Ojjeh Azziz, Pachod Noël, Pachod Patrick, Parveaux Albert, Pelisson Gérard, Petilaire Séverine, Pinturault Claude, Rochedy Michel,
Une démarche à rationaliser," Ed., d'Organisation, (2001), pp. 63-82.

[11] F. Jallat, "Innovation Dans les Services: Les Facteurs de Succès," Décisions Marketing, Vol. 2, 1994, pp. 23-30.

[12] E. C. Martins and F. Terblanche, "Building Organisational Culture that Stimulates Creativity and Innovation," European Journal of Innovation Management, Vol. 6, No. 1, 2003, pp. 64-74. doi:10.1108/14601060310456337

[13] W. Reinartz and V. Kumar, "The Mismanagement of Customer Loyalty," Harvard Business Review, Vol. 72, No. 2, July 2002, pp. 164-174.

[14] “Le Marketing Relationnel,” HTR, December 2004.
Rochedy Nicolas, Ruffier Jacky, Saxe Yvette, Tournier Catherine, Tournier Eric, Tournier Nicolas, Toussaint Josiane, Trauchessec Jacques, Vidoni Jean-Christophe, Zanon Denis, Ziegler Michel.

\section{Hotels Interviewed and/or Quoted}

Les Airelles, L'Annapurna, Le Bateau Ivre, Le Carlina, Le Chabichou, Le Cheval Blanc, Le Denali, Le Génépi, Le Kilimandjaro, Le Lana, Le Manali, Le Melezin, Le Mercure, Les Neiges, Le Paddock, Le Palace des Neiges, La Pomme de Pin, Le Saint-Joseph, Le Saint-Roch, La Saulire, La Sivolière, Le Tremplin. 